Provided for non-commercial research and education use. Not for reproduction, distribution or commercial use.

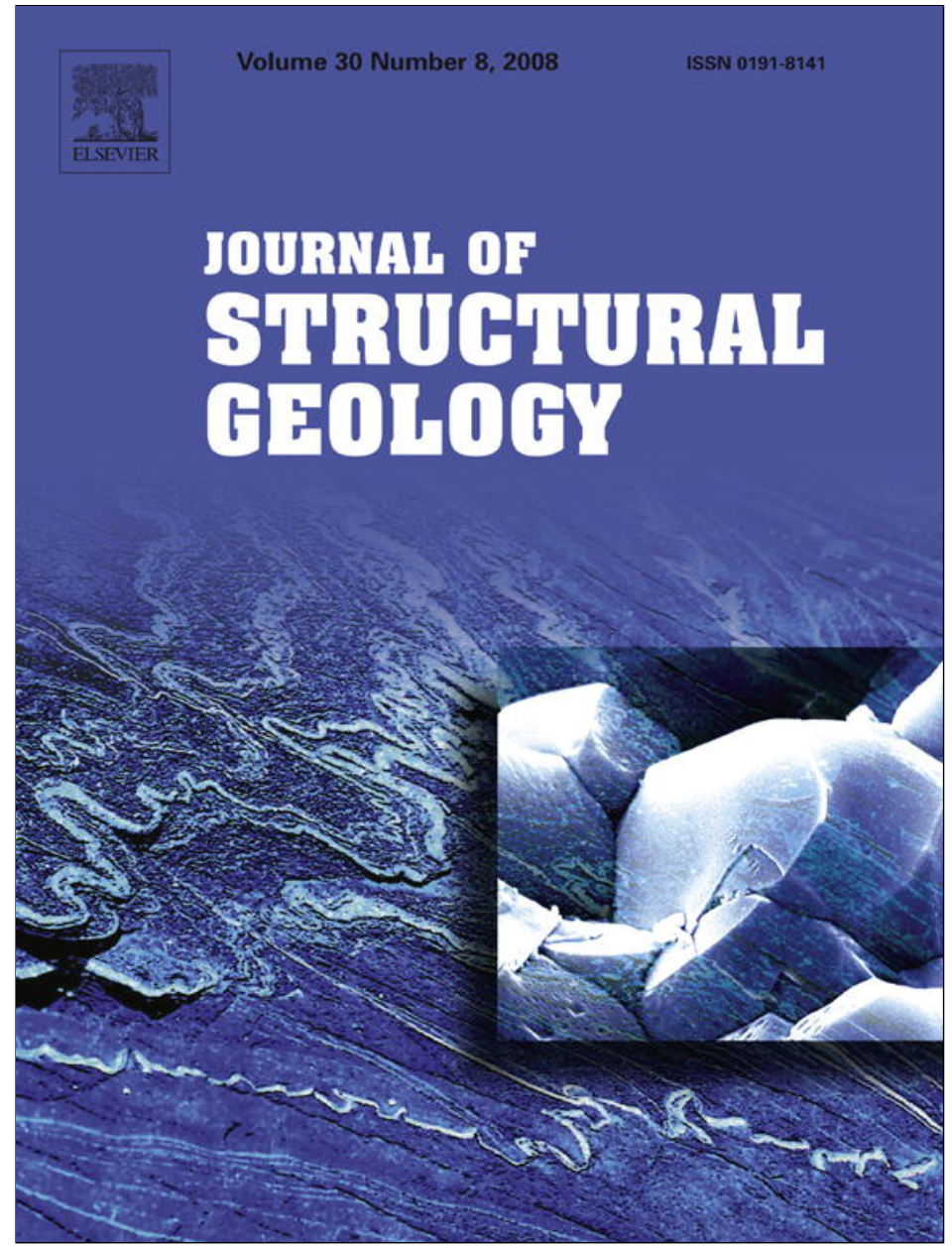

This article appeared in a journal published by Elsevier. The attached copy is furnished to the author for internal non-commercial research and education use, including for instruction at the authors institution and sharing with colleagues.

Other uses, including reproduction and distribution, or selling or licensing copies, or posting to personal, institutional or third party websites are prohibited.

In most cases authors are permitted to post their version of the article (e.g. in Word or Tex form) to their personal website or institutional repository. Authors requiring further information regarding Elsevier's archiving and manuscript policies are encouraged to visit:

http://www.elsevier.com/copyright 


\title{
Contractional kink bands formed by stress deflection along pre-existing anisotropies? Examples from the Anglo-Brabant Deformation Belt (Belgium) and the North Dobrogea Orogen (Romania)
}

\author{
Timothy N. Debacker ${ }^{\mathrm{a}, *}$, Antoneta Seghedi ${ }^{\mathrm{b}}$, Marcel Belmans ${ }^{\mathrm{a}}$, Manuel Sintubin ${ }^{\mathrm{c}}$ \\ ${ }^{a}$ Geology and Pedology, Universiteit Gent, Krijgslaan 281, S8, 9000 Gent, Belgium \\ ${ }^{\mathrm{b}}$ Geological Institute of Romania, 1 Caransebeş St., 012271 Bucharest 32, Romania \\ ${ }^{\mathrm{C}}$ Geodynamics and Geofluids Research Group, Katholieke Universiteit Leuven, Celestijnenlaan 200E, 3001 Leuven, Belgium
}

\section{A R T I C L E I N F O}

\section{Article history:}

Received 7 August 2007

Received in revised form 11 April 2008

Accepted 28 April 2008

Available online 2 May 2008

\section{Keywords:}

Brabant Massif

Dobrogea

Cleavage

Kink band

Slate belt

Stress

\begin{abstract}
A B S T R A C T
Kink bands within two slate belts, the Anglo-Brabant Deformation Belt (Belgium) and the North Dobrogea Orogen (Romania), reveal similar problems with respect to linking kink band geometries to expected palaeostress directions. In the North Dobrogea Orogen, the two opposite kink band sets of two different systems of conjugate kink bands develop for a wide variety of cleavage orientations. In the Anglo-Brabant Deformation Belt, the occurrence of the two opposite kink band sets of a conjugate kink band system opposes the expected occurrence. In both cases, this can be attributed to stress deflection along a pre-existing anisotropy. Moreover, the presence of kink bands in the North Dobrogea Orogen with curving kink axes (and curving kink band boundaries) also puts doubt on the direct relationship between kink band geometry and stress.

The idea of stress deflection along a pre-existing anisotropy and the strong control of the pre-existing anisotropy on the kink band geometry and orientation has important implications for the use of kink bands as regional palaeostress indicators. Depending on the relative intensity and relative orientation of the pre-existing fabrics (here bedding and cleavage), different mechanisms of kink band development may operate. Depending on the mechanism, different solutions in terms of inferred palaeostress direction may exist.
\end{abstract}

(c) 2008 Elsevier Ltd. All rights reserved.

\section{Introduction}

One of the ultimate goals for structural geologists is determining the stresses responsible for a given deformation. However, as there is generally no direct relationship between strain and stress in naturally deformed rocks, this is not an easy task. In particular, this is the case within ductile to brittle-ductile deformed regions, in which the main deformation features are folds and cleavage. Within such regions, even when after intensive analysis the principal strain axes become known, determining the principal stress axes will be virtually impossible, as generally these will not coincide with the principal strain axes. Although essentially being small-scale folds, kink bands are thought to form an exception. Kink bands are narrow zones (bands) of angular, straight-limbed folds (kinks), forming on a well-developed, pre-existing planar anisotropy. Experimental work pointed out a direct relationship between

\footnotetext{
* Corresponding author. Tel.: +329264 4609.

E-mail addresses: timothy.debacker@ugent.be (T.N. Debacker), antoneta@igr.ro (A. Seghedi), manuel.sintubin@geo.kuleuven.be (M. Sintubin).
}

kink band geometry and the principal stress directions (e.g. Paterson and Weiss, 1962, 1966; Donath, 1968; Anderson, 1974; Gay and Weiss, 1974). These experiments showed that, at high confining pressures, when the maximum compressive stress is (sub-)parallel to the strong planar anisotropy, a symmetrical conjugate system of two sets of kink bands with opposing asymmetry will form (Figs. 1 and 2). If the maximum compressive stress becomes slightly oblique to the anisotropy only one set of kink bands will develop (Figs. 1 and 2). This slight obliquity, however, varies strongly with the author, as shown in Fig. 2. In addition, an intermediate stage exists, in which the two kink band sets of the conjugate system are asymmetrically developed (see Figs. 1 and 2). On the basis of these results, in combination with field observations (e.g. Ramsay, 1962), several methods have been proposed for determining palaeostress direction from kink band geometry. This was done not only for simple, "two-dimensional" conjugate kink band systems (i.e. kink axes and intersection lineation of kink band boundaries of both sets lie in the foliation plane, such as described by Johnson, 1956), but also for the more complex "three-dimensional" conjugate kink band systems (conjugate sets with crossing kink axes; e.g. Ramsay, 1962; Dewey, 1965; Ramsay and Huber, 1987; Kirschner and Teixell, 1996) 

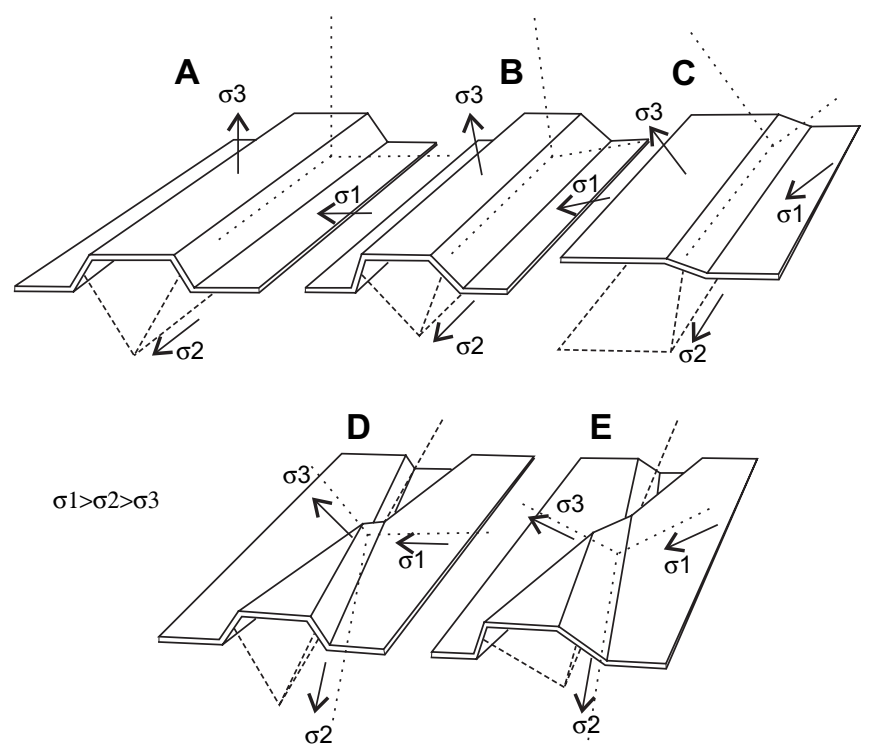

Fig. 1. Five possible kink band geometries and their relationship with the principal stress directions, taken from Ramsay and Huber (1987; cf. Ramsay, 1962). Most natura conjugate kink band systems belong to the types depicted in $\mathrm{D}$ and $\mathrm{E}$, instead of the idealised types depicted in A and B (Ramsay, 1962).

and even for a single set of kink bands (Fig. 1). An overview of the different methods can be found in Srivastava et al. $(1998,1999)$. Consequently the kink band geometry has been used in quite a number of studies for determining palaeostress direction (e.g. Kleist, 1972; Hobson, 1973; Verbeek, 1978; Murphy, 1988; Pratt, 1992; Konopasek et al., 2001; Sharma and Bhola, 2005; and examples in Srivastava et al., 1998, 1999).

One necessity for kink band development is the presence of a strong planar anisotropy (e.g. Paterson and Weiss, 1962; Ramsay, 1962; Anderson, 1964; Cobbold et al., 1971). Even if a direct link between kink band geometry and palaeostress is assumed, the question can be raised whether the pre-existing local anisotropy may have influenced the (far-field) stress directions (cf. Zandvliet, 1960; Ramsay, 1962; Cobbold et al., 1971; Donath, 1972; Murphy, 1988; Konopasek et al., 2001). This is examined by means of an analysis of contractional kink bands from two slate belts in which the orientation of the main, kinked anisotropy gradually changes on a scale exceeding that of the kink bands. Following the experimental results, in the presence of a (far-field) palaeostress of constant orientation, this large-scale change in anisotropy orientation should be reflected by the kink band geometry.

Angle external foliation-maximum compressive stress

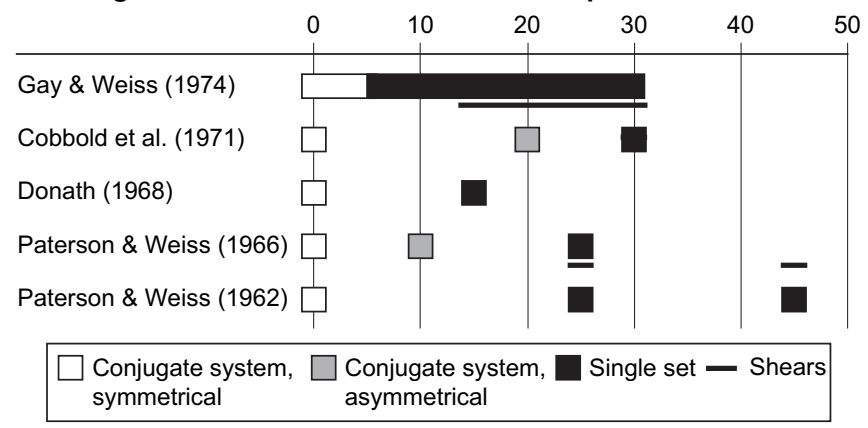

Fig. 2. Schematic overview of the experimental development of kink bands and shears in function of the angle between external foliation and maximum compressive stress.

\section{Geological setting}

\subsection{Anglo-Brabant Deformation Belt (Belgium)}

The Anglo-Brabant Deformation Belt (Fig. 3) is a poorly exposed NW-SE-trending Lower Palaeozoic slate belt, composed of lowgrade lowermost Cambrian to upper Silurian siliciclastic sequences, situated within the subsurface of $\mathrm{N}$-Belgium and SE-England (Van Grootel et al., 1997). Within the Belgian part of this slate belt, called the Brabant Massif, the deformed Lower Palaeozoic sequences are unconformably overlain by subhorizontal to gently dipping, virtually undeformed, diagenetic Middle Devonian and younger sequences (Legrand, 1968; De Vos et al., 1993; Van Grootel et al., 1997; Verniers et al., 2002). Within the Brabant Massif, there is only evidence for one (pre-kink band) single-phase progressive deformation event, called the Brabantian deformation, which took place between the late Llandovery and the Middle Devonian (Debacker, 2001; Verniers et al., 2002; Debacker et al., 2005a and references therein). The main features associated with this deformation event are folds with a moderately to well-developed cogenetic cleavage (e.g. Sintubin, 1997, 1999; Debacker, 2001; Debacker et al., 2005a and references therein).

The kink bands, investigated in the present study, occur within the southern, Silurian rim of the Brabant Massif, directly below the Middle Devonian angular unconformity (Fig. 3; Vandenven, 1967; Debacker et al., 1999; Belmans, 2000; Debacker, 2001). This Silurian rim, predominantly consisting of pelitic, distal turbidite deposits (Verniers and Van Grootel, 1991), is characterised by gentle to close, upright to moderately inclined, decametre- to hectometre-scale folds, with well-developed convergent cleavage fans (Kaisin, 1933; Mortelmans, 1953; Legrand, 1967; Sintubin, 1997, 1999; Debacker et al., 1999). Although the convergent cleavage fans were initially attributed to a poly-phase deformation (Kaisin, 1933; Mortelmans, 1953; Vandenven, 1967; Legrand, 1967), more recent studies show that this fanning is much more likely the result of a single-phase progressive deformation (Debacker et al., 1999; Belmans, 2000; Debacker, 2001, 2002; Herbosch et al., 2002). Within these Silurian sequences, two sets of contractional kink bands occur (Vandenven, 1967; Belmans, 2000; Debacker, 2001; Herbosch et al., 2002). The best examples occur within the Vichenet section, situated within the Orneau valley, directly south of Gembloux. This section consists of folded and cleaved distal turbidite deposits (predominantly $\mathrm{Te}$ and Tde sequences of Bouma, 1962) with intercalated laminated hemipelagites belonging to the Wenlock Vichenet Formation (Herbosch et al., 2002; cf. Verniers et al., 2001).

\subsection{North Dobrogea Orogen (Romania)}

Dobrogea is situated in the southeasternmost part of the Romanian Carpathian foreland, between the Black Sea and the Danube River. It consists of three major units, North-, Central and South-Dobrogea (Fig. 4). The latter represent two blocks of the Moesian platform, whereas North Dobrogea forms a narrow NWSE-trending deformation belt, the North Dobrogea Orogen (Seghedi, 2001; Hippolyte, 2002; and references therein). Within the Palaeozoic siliciclastic sequences of the North Dobrogea Orogen, two main zones can be distinguished: the Macin zone to the southwest and the Tulcea zone to the northeast. Both zones are characterised by folds and a steep NW-SE-trending cleavage.

Within the Tulcea zone, in which indications exist for a polyphase deformation history, kink bands have only locally been observed. In contrast, the Macin zone (Fig. 4) has abundant kink bands and a much better developed cleavage. The Macin zone is characterised by a pervasive, subvertical to steeply NE-dipping cleavage, cogenetic with the upright to steeply inclined, subhorizontal to gently plunging folds. The sense of overthrusting of 


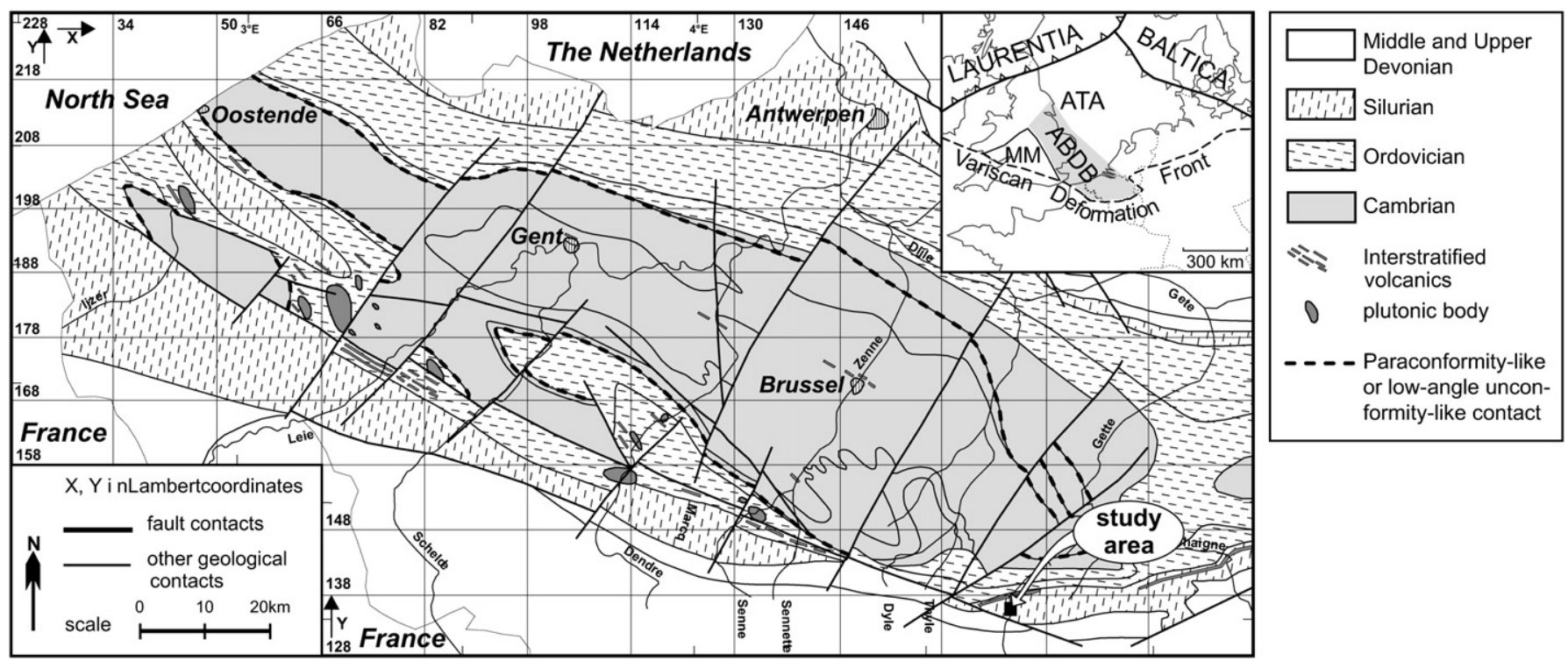

Fig. 3. Geological subcrop map of the Brabant Massif (after De Vos et al., 1993 and Van Grootel et al., 1997) with the position of the study area. The upper right inset shows the position of the Brabant Massif within the Anglo-Brabant Deformation Belt (ABDB) along the NE-side of the Midlands Microcraton (MM) in the context of Avalonia (ATA), Baltica and Laurentia.

Cambrian quartzites and the asymmetry of the thrust-related folds match the asymmetry of the cleavage and cleavage-related folds. In addition, tectonic polarity always matches the stratigraphic sense of younging. Hence, in contrast to the Tulcea zone, there is evidence for only one (pre-kink band) deformation phase. Around lower Permian calc-alkaline granites cleavage is overprinted by contactmetamorphism, thus indicating a Late Carboniferous - early Permian age for cleavage development (post-depositional to the Carapelit Formation) (e.g. Seghedi, 2001). The only features reflecting a minor, post-cleavage ductile to brittle-ductile deformation in the Macin zone are the commonly occurring contractional kink bands. The kink bands, analysed in the present study, are taken from the Macin zone, from 6 large outcrops comprising siliciclastic sequences ranging from the Silurian Cerna Formation up to the Carboniferous Carapelit Formation (Fig. 4).

\section{Observations}

\subsection{Anglo-Brabant Deformation Belt (Belgium)}

The Vichenet section (Fig. 5) contains a faulted, hectometrescale, subhorizontal to gently W-plunging, upright synform that comprises several decametre- to metre-scale parasitic folds and shows a well-developed convergent cleavage fanning (Mortelmans, 1953; Belmans, 2000; Herbosch et al., 2002). Two sets of kink bands occur: a set with a top-to-the-N asymmetry, having subhorizontal to moderately N-dipping kink band boundaries (Fig. 6C), and a set with a top-to-the-S asymmetry, having subhorizontal to gently S-dipping kink band boundaries (Fig. 6A, B). Both sets have relatively straight kink band boundaries, and widths ranging from a few millimetres to $\sim 3 \mathrm{~cm}$ (Fig. 6). The two kink band sets have
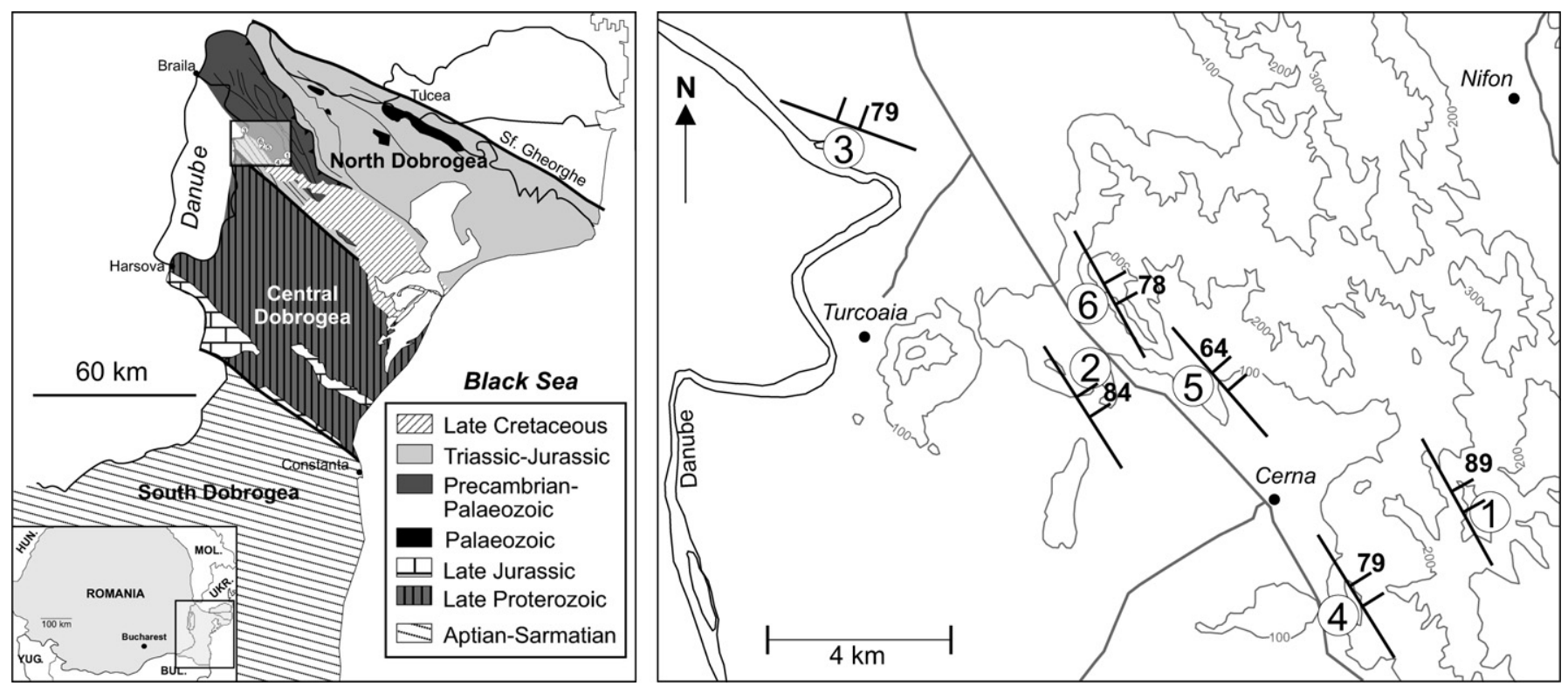

Fig. 4. Left: geological subcrop map of Dobrogea (E-Romania; see lower inset), showing the position of the Macin zone. Right: simplified topographic map of the Macin zone, showing the position of the six outcrops studied and the mean cleavage orientation in each outcrop. 


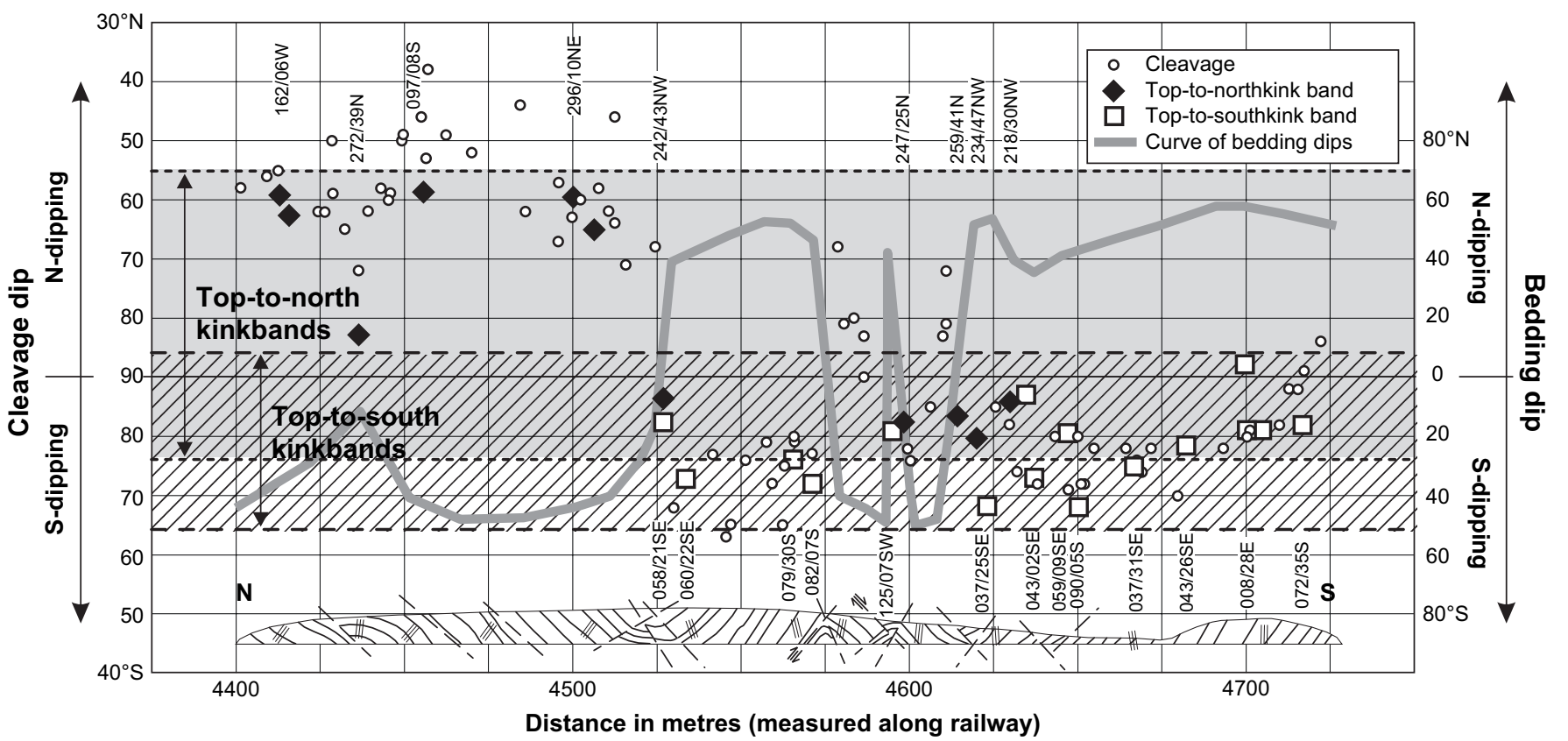

Fig. 5. Graph showing the change of cleavage dip along the Vichenet section (Anglo-Brabant Deformation Belt), on which the occurrence of the measured kink bands has been plotted. Note the preferred position of the top-to-the-N and top-to-the-S kink bands in terms of cleavage dip. Conjugate systems are expected and observed in the zone of overlap (cleavage dips $77^{\circ} \mathrm{S}$ to $86^{\circ} \mathrm{N}$ ). Also included are a section, a curve of bedding dip (dip scale on the right), as well as the orientations of the kink band boundaries (strike/dip orientations written on top and bottom of graph).

a restricted occurrence (Fig. 5). The set with a top-to-the-N asymmetry occurs where cleavage is subvertical to moderately $\mathrm{N}$ dipping (i.e. S-dipping fold limbs) and the set with a top-to-the-S asymmetry is present where cleavage is subvertical to steeply S-dipping (i.e. N-dipping fold limbs). A conjugate system of both sets is only observed where cleavage is subvertical to steeply S-dipping (i.e. around the fold hinge zones). In several places in the fold limbs, cleavage shows a strong refraction across the thin laminated hemipelagites in between the Te-turbidite sequences (see Fig. 6D). In each limb, the asymmetry of this refraction opposes the asymmetry of the kink band set present, thus resembling the missing set of a conjugate system. The bedding-parallel orientation, the continuous nature, and the restricted occurrence within laminated hemi-pelagic intervals indicate, however, that these changes in cleavage orientation are unlikely to represent kink bands.

The kink axes of both kink band sets lie within the external foliation plane (cleavage plane), and are at low angles to subparallel to the fold hinge lines and cleavage/bedding intersection lineation (Fig. 7). However, a slight difference in plunge exists between the axes of both sets. In addition, the kink band boundaries of both sets are slightly oblique to the regional trend, and the mean kink band boundary intersection lineation is slightly oblique to the kink axes, the fold hinge lines, and the cleavage/bedding intersection lineation (Fig. 7). This implies that, around the fold hinges, the two sets form a conjugate kink band system with (slightly) crossing kink axes (see Fig. 1D; cf. Ramsay, 1962 and Ramsay and Huber, 1987).

Fig. 8 shows the kink band data plotted on a kink band triangle of Srivastava et al. (1998), on which we added curves of expected volume change due to kink band development (Anderson, 1964; Ramsay and Huber, 1987). There is no significant difference between both kink band sets in terms of internal geometry. Both sets plot in the same part of the diagram and suggest a slight to moderate volume increase due to kink band development. Although such a volume increase (dilation) is often accommodated by the development of fractures and veins (Anderson, 1964; Ramsay and Huber, 1987), our examples do not show evidence for this. Possibly, much of the dilation occurred at relatively low fluid pressures, under conditions unfavourable for quartz precipitation, resulting in a less obvious extension (e.g. a more homogenous extension along the individual cleavage domains; Fig. 6A).

On the basis of the conjugate system, a subvertical to steeply Splunging maximum compressive stress may be inferred, acting
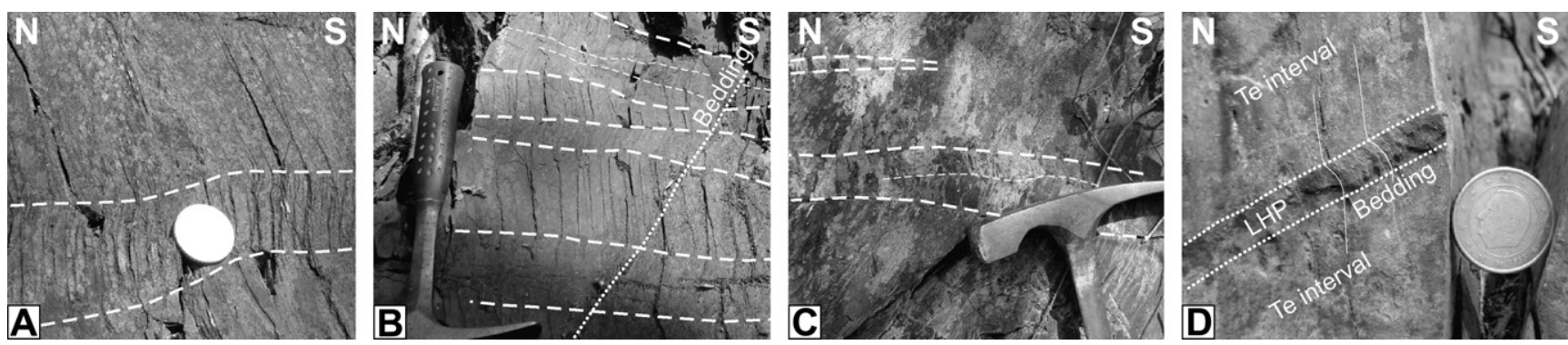

Fig. 6. Kink bands along the Vichenet section (Anglo-Brabant Deformation Belt). For clarity, the kink band boundaries have been traced (thick white dashed line); occasionally subordinate kink band boundaries can be distinguished within the larger kink bands (thin white dashed line). (A) Top-to-S kink band at $\sim 4700 \mathrm{~m}$ ( 50 eurocent coin for scale); (B) top-to-S kink bands at $\sim 4700 \mathrm{~m}$, with bedding trace indicated (hammer for scale); (C) top-to-N kink bands at $\sim 4460 \mathrm{~m}$ (hammer for scale); and (D) pronounced cleavage refraction across a laminated hemipelagite (LHP) in between two turbidite-intervals (Te interval) at $\sim 4650 \mathrm{~m}$; for clarity, also cleavage has been traced (50 eurocent coin for scale). 
+ Pole to external cleavage (outside of kink band)

$\times$ Pole to internal cleavage (inside kink band)

- Pole to kink band boundary of top-to-north kink band

$\square$ Pole to kink band boundary of top-to-south kink band

- Kink axis of top-to-north kink band

- Kink axis of top-to-south kink band

........... Mean external cleavage orientation

- Mean kink band boundary (Mkbb, N: top-to-north)

- - - Best fit girdle through cleavage and kink band boundary poles Contours of poles to bedding:

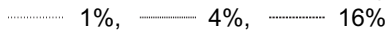

.... - Best fit girdle through bedding poles

O Regional fold axis

$\frac{n}{4}$ Regional cleavage fan axis

Maximum principal stress direction, being the bisector of the obtuse angle of conjugate kink band boundaries

Maximum principal stress direction, in case the principal stress directions are co-axial with cleavage (given by intersection of mean cleavage and best fit girdle)

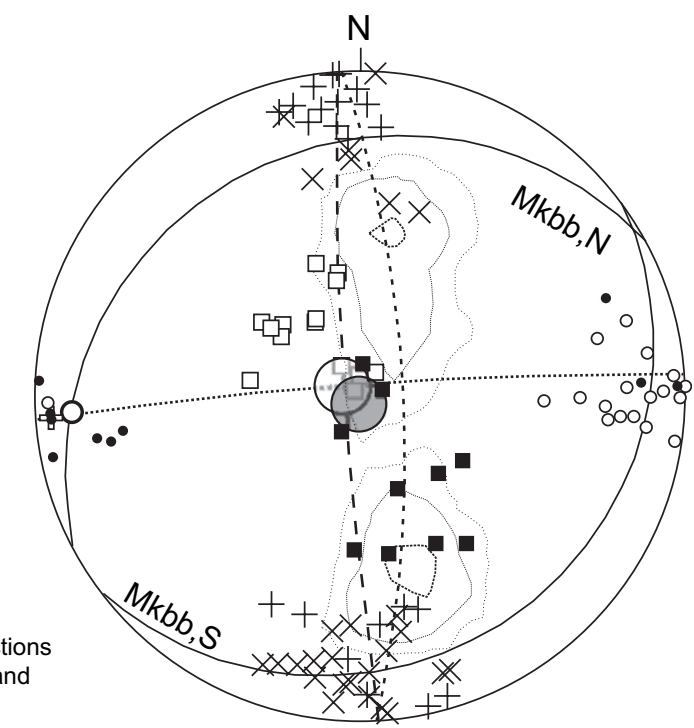

Fig. 7. Lower-hemisphere equal area projection of cleavage, folds and kink bands along the Vichenet section (Anglo-Brabant Deformation Belt), on which the inferred maximum principal stress direction (or maximum shortening direction) has been plotted.

along the locally subvertical to steeply S-dipping anisotropy (Figs. 7 and 9; e.g. Ramsay, 1962). As expected from experiments (e.g. Paterson and Weiss, 1962, 1966), such a maximum principal stress orientation should give rise to kink bands with a top-to-the-N asymmetry on a S-dipping cleavage (N-dipping limb) and kink bands with a top-to-the-S asymmetry on a N-dipping cleavage
(S-dipping limb; see ideal case of Murphy, 1988) (Fig. 9A). In contrast, the reverse is observed: top-to-the-N kink bands on a N-dipping cleavage (S-dipping limb) and top-to-the-S kink bands on a S-dipping cleavage (N-dipping limb) (Figs. 5 and 9B, C). A similar situation occurs at Ronquières, situated in the Sennette valley, $33 \mathrm{~km}$ to the WNW of the study area (Fig. 3). At Ronquières,

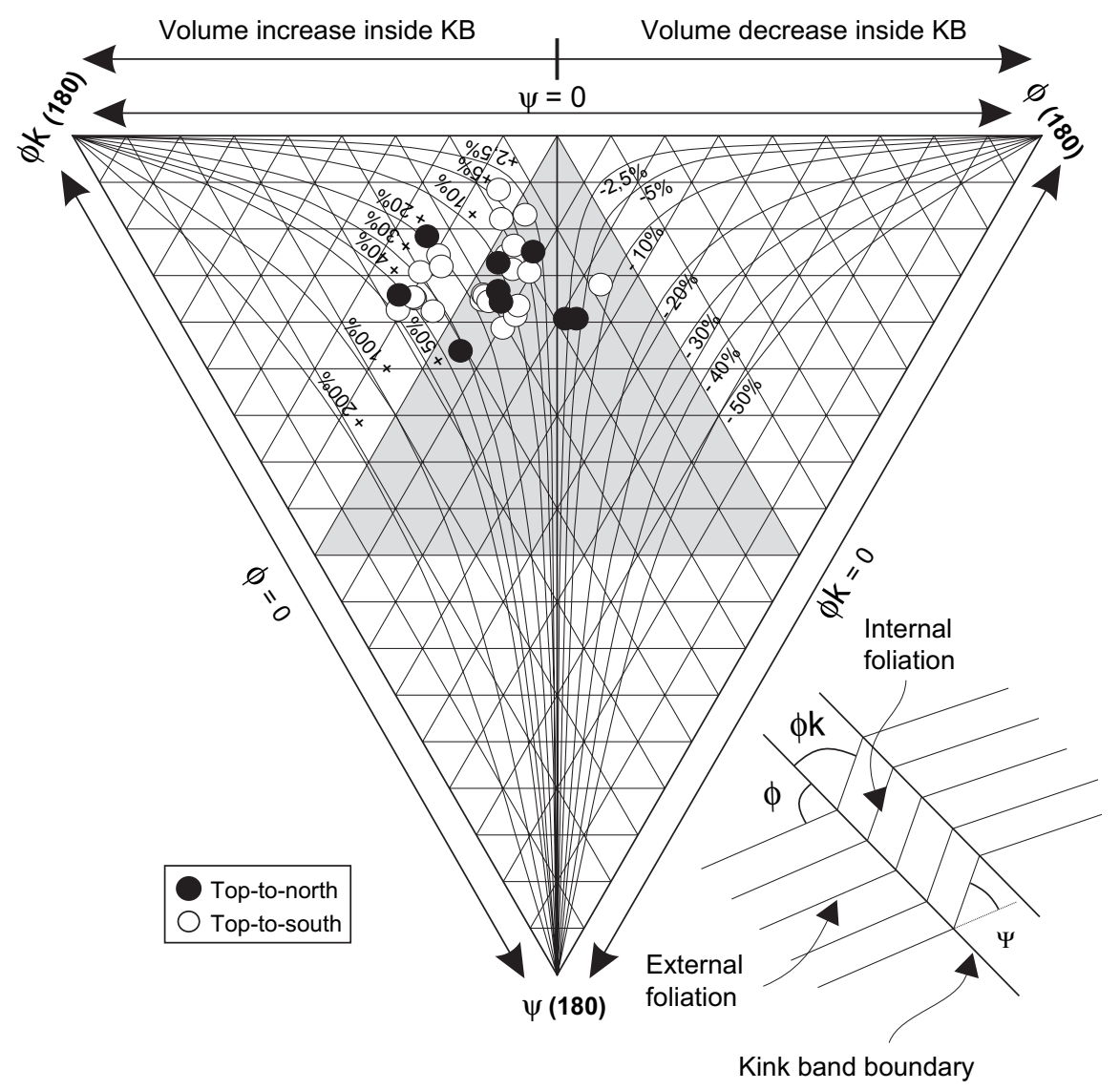

Fig. 8. Kink band data of the Vichenet section (Anglo-Brabant Deformation Belt), plotted on a kink band triangle of Srivastava et al. (1998), with added curves of expected volume change due to kink band development, given by $\sin \varphi_{\mathrm{k}} / \sin \varphi-1$ (Anderson, 1964; Ramsay and Huber, 1987). 
A

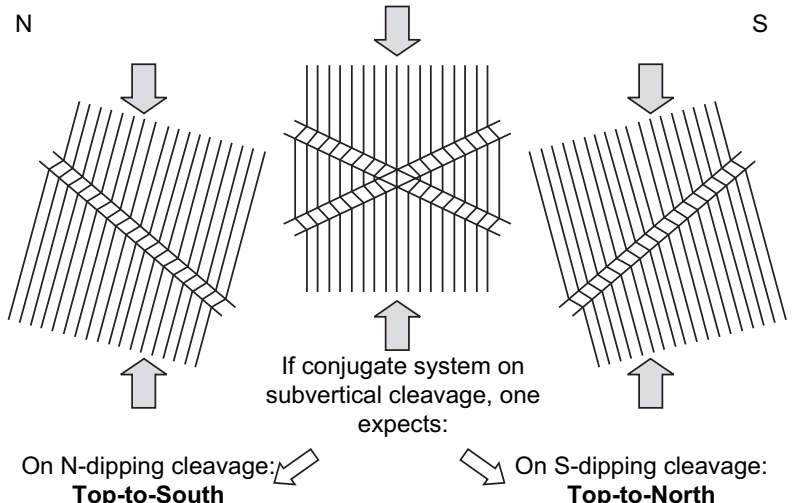

B

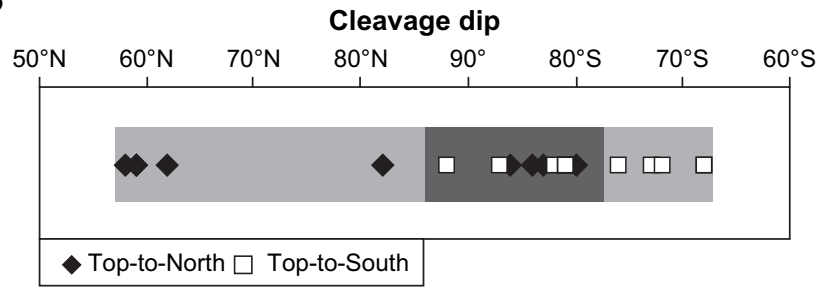

C
$\mathrm{N}$

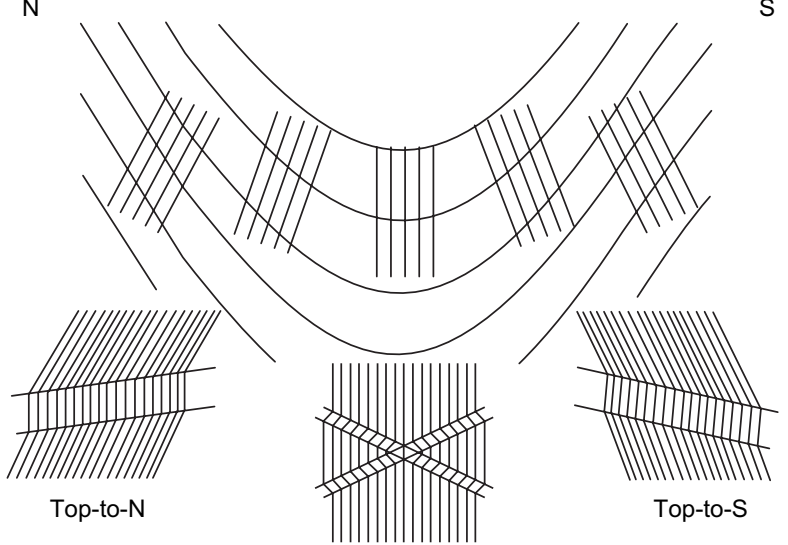

Fig. 9. Schematic representation of observations and problems regarding kink bands in the Vichenet section (Anglo-Brabant Deformation Belt). (A) Expected kink band geometries for changing cleavage dips under the influence of a subvertical maximum compression. (B) Relative occurrence of different types of kink bands with respect to cleavage dip. The zone of cleavage dips in which both sets, whether or not as a conjugate system, have been encountered (see zone of overlap in Fig. 5) is marked in dark grey. In pale grey, the zone of cleavage dips is outlined for which the observations seemingly contradict the theory in A. (C) Schematic representation of the data presented in B (compare with A).

poorly developed kink bands occasionally occur within lower Ludlow distal turbidite sequences (Debacker et al., 1999). Most of the kink bands have a top-to-the-S asymmetry and affect the $\mathrm{S}$-dipping cleavage on the $\mathrm{N}$-dipping fold limbs. However, within the S-dipping fold limbs, where cleavage dips to the north, very locally kink bands occur with a top-to-the-N asymmetry (Debacker, 2001 ), resulting in an overall geometry identical to that of the Vichenet section.

\subsection{North Dobrogea Orogen (Romania)}

Within the Macin zone, forming the SW-part of the North Dobrogea Orogen (outcrops 1-6 on Fig. 4), four sets of contractional kink bands are recognised, with kink band widths ranging from a few millimetres to $\sim 10 \mathrm{~cm}$. These sets are, in decreasing order of abundance (1) a top-to-the-NE set, (2) a sinistral set, (3) a dextral set and (4) a top-to-the-SW set (Figs. 10 and 11). Although the topto-the-NE set and the sinistral sets usually dominate the outcrops, most of the outcrops show that these four sets of kink bands form two conjugate kink band systems. One conjugate system has subhorizontal kink axes (the top-to-the-NE and the top-to-the-SW sets, called the subhorizontal system; e.g. Fig. 10B-D) and the other conjugate system has subvertical to steeply plunging kink axes (the sinistral and dextral sets, called the subvertical system). In the cases where cross-cutting relationships could be observed, the subhorizontal system is deformed by the subvertical system (Fig. 10E, F). Both the subhorizontal and the subvertical conjugate systems are mostly symmetric, but have crossing kink axes; i.e. the kink axes of both sets of a conjugate system are usually not parallel to each other, nor are they parallel to the intersection lineation of the kink band boundaries (Fig. 10B, D; cf. Ramsay, 1962; Dewey, 1965; Ramsay and Huber, 1987; see also Fig. 1D). A further particularity of these kink bands is their often periclinal and anastomosing nature (Fig. 10D, G; cf. Kirschner and Teixell, 1996). In addition, occasionally the kink bands have markedly curved kink band boundaries (cf. Verbeek, 1978) and may show a change in kink axis orientation of more than $30^{\circ}$ (Fig. $10 \mathrm{H}$ ).

On the kink band triangle of Srivastava et al. (1998), with added curves of expected volume change (Anderson, 1964; Ramsay and Huber, 1987), only minor differences are observed between the four kink band sets (Fig. 12). The top-to the-NE set has a smaller $\varphi$ and is much more abundant than the top-to-the-SW set, and the sinistral set is slightly more abundant than the dextral set and generally has a slightly higher $\varphi$. This suggests a slightly asymmetric nature of the conjugate systems, which is not readily apparent in outcrop (cf. Fig. 10C). All sets cluster in the same part of the diagram and most suggest a slight to moderate volume increase due to kink band development. However, in contrast to the data from the AngloBrabant Deformation Belt, the clusters show a much larger spread. This is particularly the case for the top-to-the-NE kink bands in the Bujoare and Cerna formations. This spread is possibly related to the anastomosing, curvilinear nature of many of the kink bands.

The different kink band sets within the North Dobrogea Orogen do not appear to show a restricted occurrence. Although cleavage orientation shows significant changes between outcrops and, to a lesser extent also within individual outcrops, conjugate systems occur in most outcrops. In nearly all outcrops both kink band sets of the subhorizontal and subvertical conjugate systems have been observed, seemingly irrespective of cleavage orientation (see Figs. 11 and 13).

On the basis of the conjugate nature, a subvertical to steeply $\mathrm{N}$-plunging maximum compressive stress can be inferred as a cause for the subhorizontal system, whereas a NW-SE-directed maximum compressive stress orientation, subparallel to the long axis of the North Dobrogea Orogen ( cleavage trend), can be inferred for the subvertical system (Fig. 11). However, the range of cleavage orientations in which both sets of a conjugate system are observed is surprisingly large (Fig. 13B, C). As expected from previous work (e.g. Paterson and Weiss, 1962; cf. Ramsay and Huber, 1987; see Fig. 1) the inferred maximum principal stress orientation should give rise to a top-to-the-NE set on a SW-dipping cleavage and a topto-the-SW set on a NE-dipping cleavage (Fig. 13A). Similarly, for the subvertical system an inferred NW-SE-directed compression should give rise to a dextral set on the cleavage planes with a more northerly trend, and to a sinistral set on the cleavage planes with a more westerly trend (Fig. 13A). Using this reasoning, the expected occurrence of conjugates can be marked on the graphs of Fig. 13. This results in a very large spread of cleavage orientations, both within individual outcrops and between different outcrops (Fig. 13B, C). 

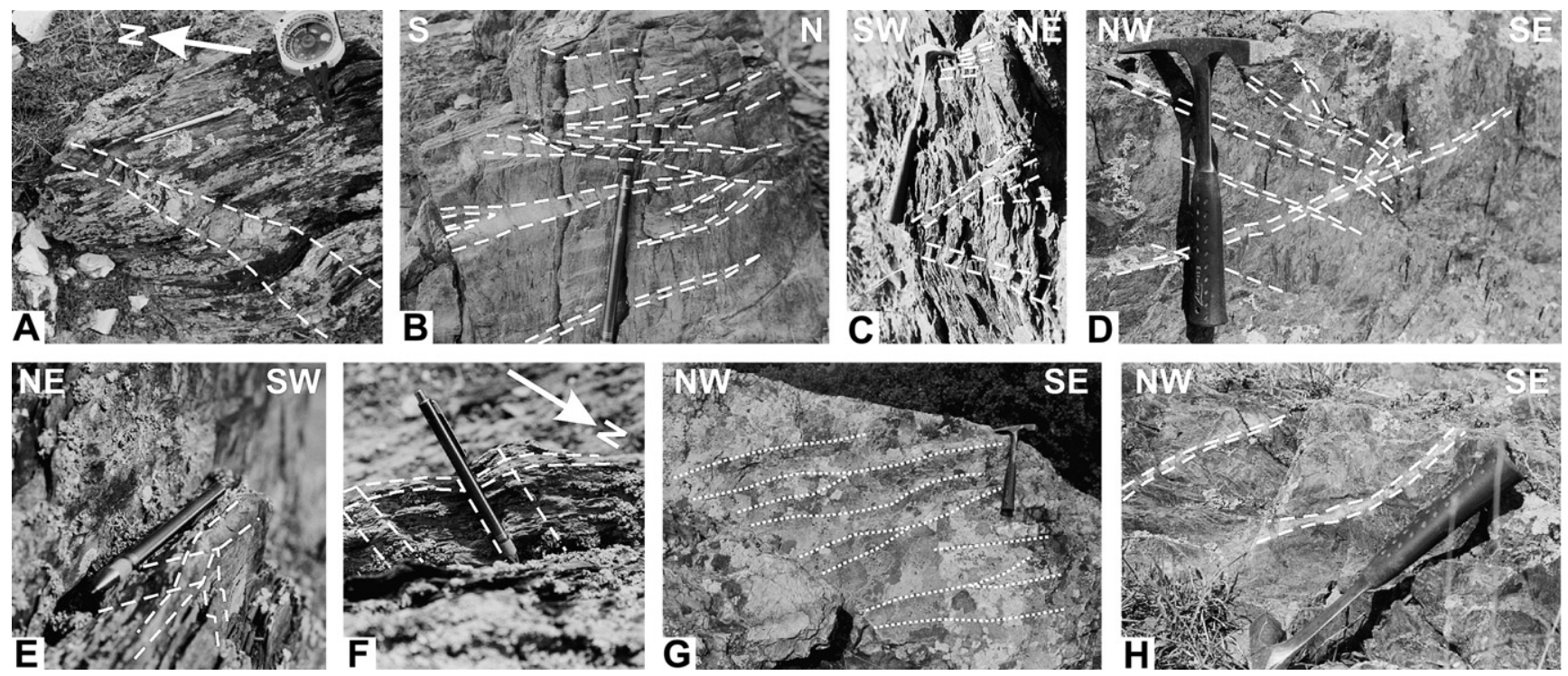

Fig. 10. Kink bands from the Macin zone, North Dobrogea (Romania). For clarity, the kink band boundaries have been traced (thick white dashed line). (A) Sinistral kink band in outcrop 4 (Dalchi Bair or Cerna Hill; pen and compass for scale); (B) oblique view of closely spaced top-to-the-NE and top-to-the-SW kink bands, forming a conjugate system with crossing kink axes (outcrop 6: Priopcea Hill; Cerna Fm., Silurian; pen for scale); (C) profile view of top-to-the-NE and top-to-the-SW kink bands, forming a slightly asymmetric conjugate system (outcrop 3: Igliţa; Bujoare Fm., Silurian-Lower Devonian; hammer for scale); (D) cleavage affected by top-to-the-NE and top-to-the-SW kink bands, forming a conjugate system with crossing kink axes; note bifurcation (outcrop 3: Igliţa; Bujoare Fm., Silurian-Lower Devonian; hammer for scale); (E) top-to-the-NE kink band, with axis subparallel to pen, affected by a NNE-SSW-trending sinistral kink band (outcrop 2: Chior Tepe; Bujoare Fm., Silurian-Lower Devonian; pen for scale); (F) top-to-the-NE kink band, affected by a NNE-SSW-trending sinistral kink band, subparallel to pen (outcrop 2: Chior Tepe; Bujoare Fm., Silurian-Lower Devonian; pen for scale); (G) plan view of cleavage affected by a system of closely spaced subhorizontal kink bands; the crests of the kink folds are traced; note: rather rounded hinges, periclinal shape, curvilinear traces and anastomosing/bifurcating nature (outcrop 1: la Carapelit; Carapelit Fm., Upper Carboniferous; hammer for scale); and (H) plan view of cleavage affected by top-to-the-NE kink bands; note strong curvature of the kink axis (and kink band boundaries) (outcrop 3: Igliţa; Bujoare Fm., Silurian-Lower Devonian; hammer for scale).

\section{Discussion}

\subsection{Interpretation of the kink band data}

\subsubsection{North Dobrogea Orogen (Romania)}

In the Macin Zone, both the subhorizontal and subvertical kink band sets occur as conjugate systems for a wide variety of cleavage orientations (Fig. 13). The presence of both sets of kink bands forming a conjugate system appears to be virtually unrelated to cleavage orientation. This observation cannot be explained by questioning the conjugate nature, as this does not offer an explanation for the presence of all sets in nearly all outcrops, for different cleavage orientations.

Possibly, the orientation of cleavage changed during or after kink band development, either due to larger-scale kink band development beyond the scale of observation (e.g. Goscombe et al., 1994) or due to faulting and fault-block rotation (e.g. Pratt, 1992; Kirschner and Teixell, 1996). Indeed, later faulting events, which are likely to have occurred (e.g. Seghedi, 2001), as well as cleavage rotation by larger-scale kink band development, may offer an explanation for the markedly different cleavage orientation in the case of outcrop 3 (see Figs. 4, 11, 13 and 14). However, for the other outcrops also this scenario is unsatisfactory. The main reason for this is that cleavage orientation changes not only between different outcrops, but also within individual outcrops, and this not only in terms of cleavage strike, but also in terms of cleavage dip. This change in orientation occurs rather gradually, as in none of the outcrops separate clusters are observed in the orientation of the external foliation (see Fig. 11), something which would be expected in the case of larger-scale kinking or fault-block rotation.

A much simpler explanation is to suggest that the palaeostresses responsible for both conjugate systems (first the subhorizontal system, afterwards the subvertical system) were guided by (i.e. deflected into parallelism with) the cleavage fabric (Fig. 14). Although an influence of later fault-block rotation and cleavage rotation by larger-scale kinking cannot be ruled out completely (especially in the case of outcrop 3; cf. Pratt, 1992), stress deflection seems the most likely explanation for the observations in the North Dobrogea Orogen.

\subsubsection{Anglo-Brabant Deformation Belt (Belgium)}

In the Vichenet section, the conjugate kink band system is observed only around the fold hinges, and only one kink band set occurs in the fold limbs, with opposing asymmetries for opposing cleavage dips. The relative position of the two sets of kink bands in the fold limbs, however, is the mirror image of what is expected (compare Fig. 9A, C; also compare with Fig. 6 in Murphy, 1988). Interpreting this in terms of palaeostress, this would suggest a subvertical to steeply S-plunging maximum compressive stress within the hinges, parallel to cleavage (conjugate system), and a maximum compressive stress with a plunge which is less than the dip of the cleavage within the fold limbs (Fig. 15A). Below, several hypotheses are put forward, but only few of these are capable of adequately explaining all observations.

The observed discrepancy was noticed already by Vandenven (1967), who attributed the convergent cleavage fans to a polyphase deformation, and suggested that the kink bands formed before cleavage fan development. However, the restricted occurrence of the two opposing sets of kink bands with respect to cleavage dip suggests that this is very unlikely. Similarly, also models invoking kink band development prior to and/or during fold tightening cannot adequately explain the observations, as the restricted occurrence, the orientation and the geometries of the two sets of kink bands are not compatible with the kink bands being passively rotated during fold tightening (see Figs. 5 and 9).

A hypothesis invoking two different generations of kink bands is also unlikely, as this necessitates a rotational stress field, which should give rise to unobserved features such as different crosscutting sets of kink bands, local extensional kink bands and shear fractures (cf. Paterson and Weiss, 1966; Gay and Weiss, 1974). 


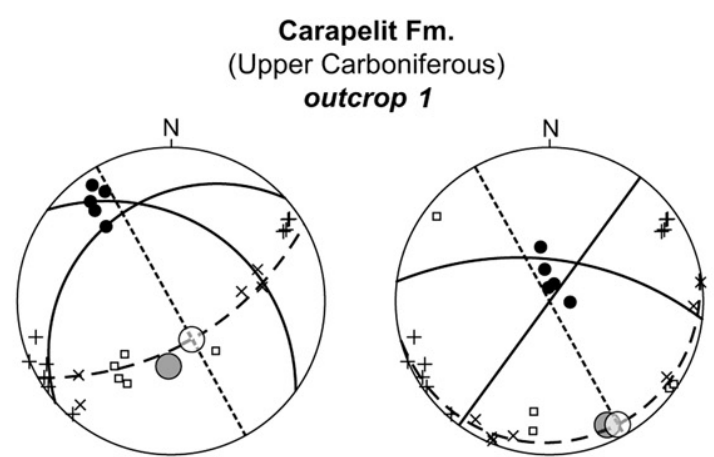

Bujoare Fm.

(Silurian - Lower Devonian) outcrop 2

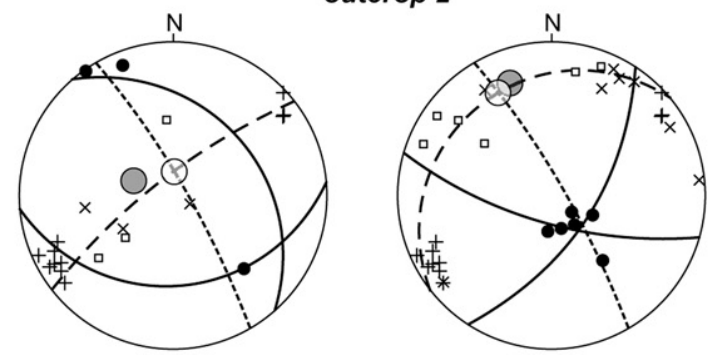

Bujoare Fm.

(Silurian - Lower Devonian) outcrop 3
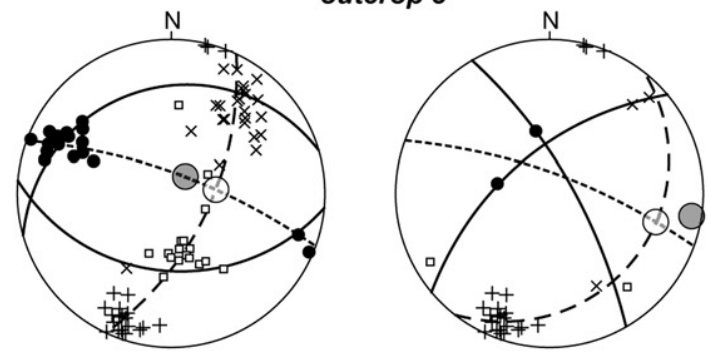

Cerna Fm.

(Silurian)

outcrops $5 \& 6$
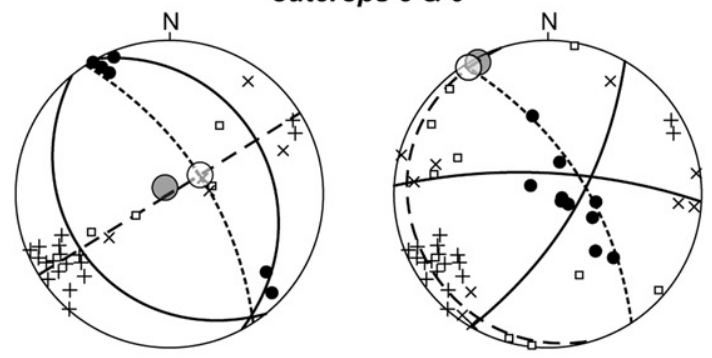

Fig. 11. Lower-hemisphere equal area projections showing cleavage, folds and kink bands in the Macin zone (North Dobrogea Orogen), on which also the inferred maximum principal stress direction (or maximum shortening direction) has been plotted.

Relating the kink bands to the complex stress patterns around the tip zones of small-displacement normal faults (cf. Johnson, 1956; Ramsay, 1962; Kleist, 1972; Pratt, 1992) is difficult to reconcile with the specific position of the kink bands within the folds. In addition, the influence and the interaction of the tip zones of different faults are expected to give rise to a much larger variety of deformation geometries.

Alternatively, three explanations can be put forward in which the pre-existing anisotropy plays an important role. (A) Possibly, throughout the folds, subvertical stress is deflected subperpendicular to bedding (Fig. 15A). This hypothesis, based on the experimental results on the relationship between stress and kink band geometry (e.g. Paterson and Weiss, 1962, 1966; Gay and Weiss, 1974), may explain both the presence of a conjugate system in the fold hinge (cleavage perpendicular to bedding) and the restricted occurrence of opposing kink band sets on opposite fold limbs (where cleavage is at high angles but not perpendicular to bedding). However, it is difficult to understand why stress would be deflected subperpendicular to bedding. A combination of microscopic observations (Belmans, 2000; Debacker, 2001), X-ray pole figure goniometry (Sintubin in Belmans, 2000 and in Debacker, 2001; cf. Debacker et al., 1999) and magnetic fabric studies (Debacker et al., 2004a, 2005b), indicate that, although the bedding fabric is still quite pronounced, the dominant fabric is the cleavage. (B) Possibly, maximum compressive stress is deflected subparallel to cleavage (Fig. 15B). This, however, should lead to a conjugate kink band system also in the fold limbs. In the fold limbs, the locally observed pronounced cleavage refraction shows an asymmetry identical to that of the missing set of the conjugate system (see Fig. 6D), and also the bedding orientation approaches that of the missing set of the conjugate system (compare angle between bedding, cleavage and kink band boundaries on Fig. 5). According to this scenario, kink bands formed under the influence of a maximum compressive stress that was guided by the cleavage plane (i.e. slightly steeper plunge than in A). This resulted in a truly recognisable conjugate system only within the fold hinges. Within the limbs, one of the kink band sets formed along the bedding anisotropy within the hemi-pelagic interval, and only appears as a pronounced cleavage refraction (Fig. 6D). Also in this scenario, kink band development took place after fold tightening and cleavage fanning, as no systematic relationship is observed between the orientation of both the top-to-the-N and top-to-the-S kink bands and cleavage and bedding orientation. (C) As a second alternative, it is suggested that maximum compressive stress was subvertical to steeply S-plunging throughout the folds (Fig. 15C). Within the fold hinges this gave rise to a conjugate kink band system. Within the limbs, however, this resulted in normal shear along the pre-existing anisotropies. In this hypothesis, beddingparallel normal shear is reflected by the pronounced cleavage refraction along the hemi-pelagic intervals. Because of the convergent cleavage fanning, cleavage in the fold limbs may have taken up the role of the second Riedel shear $\left(R^{\prime}\right)$ with respect to the bedding-parallel shear (see angles between cleavage and bedding in Fig. 5, ranging from 90 to $40^{\circ}$, with average of $\sim 70^{\circ}$ ). Several authors have indeed suggested that slip along the external foliation (here cleavage) plays an important role in kink band development (Stubley, 1990; Stewart and Alvarez, 1991). Possibly, the subvertical to steeply plunging maximum compressive stress was capable also of forming pressure solution seams at high angles to compression. The normal shear along the cleavage $\left(R^{\prime}\right)$, possibly in combination with pressure solution seams, resulted in a single set of kink bands, with an asymmetry opposing the expected asymmetry. This hypothesis may also offer an explanation for the scarcity of conjugate systems within the fold hinges and for any slight differences in orientation between the kink bands in the fold limbs and in the fold hinges. 


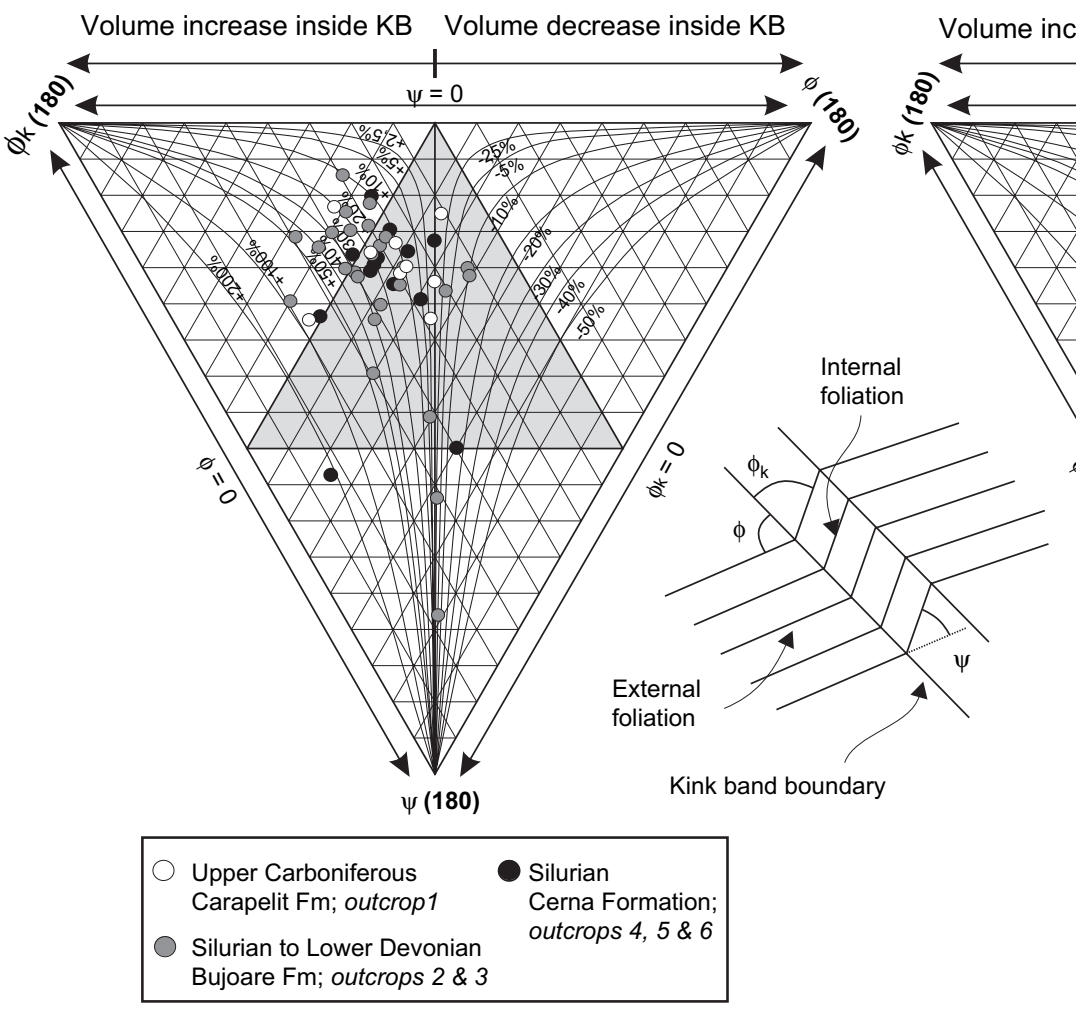

Fig. 12. Kink band data of the Macin zone, plotted on a kink band triangle of Srivastava et al. (1998), with added curves of expected volume change due to kink band development, given by $\sin \varphi_{\mathrm{k}} / \sin \varphi-1$ (Anderson, 1964; Ramsay and Huber, 1987). In the left triangle, the kink band data have been separated according to their lithostratigraphic occurrence, and in the right triangle the different types of kink bands are compared irrespective of their occurrence.

The last three hypotheses also offer an explanation for the regionally restricted occurrence of the kink bands. Thus far, within the Brabant Massif these top-to-the-N and top-to-the-S kink bands have only been observed within the Silurian deposits containing folds with well-developed convergent cleavage fans (e.g. Debacker, 2001; Herbosch et al., 2002). Possibly, the kink bands are intimately linked with the convergent cleavage fans, as only within these fans high cleavage-bedding angles exist throughout the folds within well-cleaved pelitic deposits.

4.2. Uncertainties regarding kink bands: brittle or ductile origin and formation mechanism?

Kink bands are often regarded as one of the last structures that formed (e.g. Johnson, 1956; Ramsay, 1962; Dewey, 1966; Verbeek, 1978; Sharma and Bhola, 2005). Indeed, often kink band geometries comply with the stress patterns related to faulting (e.g. Johnson, 1956; joint drags of Dewey, 1965; Kleist, 1972; Pratt, 1992) and may also match the stress patterns responsible for postcompressive normal faulting (e.g. Vichenet section and other places within Anglo-Brabant Deformation Belt; see also Debacker et al., 2004b). This does not imply, however, that these structures have a brittle nature. Also the presence of fractures along kink band boundaries, resulting from the accommodation of thickness changes due to kink band development or from later failure along the kink band boundary (Anderson, 1964; Dewey, 1966; Ramsay and Huber, 1987), is no argument for a brittle origin. In this respect, it is worth considering that experiments only resulted in kink bands at high confining pressures, much higher than those leading to shear fracture development (e.g. Anderson, 1974; cf. Paterson and Weiss, 1962; Gay and Weiss, 1974). Taking into account the above, it is hard to understand why, unlike other folds, kink bands are sometimes regarded as having a brittle origin (e.g. Johnson, 1956; Ramsay, 1962; Dewey, 1966; Sharma and Bhola, 2005).

Possibly, the use of kink bands as palaeostress indicators goes hand in hand with the idea of them being late, brittle structures. The initial experiments and field observations suggested a link with stress (e.g. Ramsay, 1962; Paterson and Weiss, 1962, 1966; Donath, 1968; Anderson, 1974; Gay and Weiss, 1974), whereas field studies demonstrated a late development, and occasionally reported a, sometimes disputed (e.g. Anderson, 1964; Murphy, 1988), relationship with faults and fractures (e.g. Johnson, 1956; Ramsay, 1962; Dewey, 1966; Kleist, 1972; Pratt, 1992), of which the use as palaeostress indicator was already known (e.g. Anderson, 1951; Angelier, 1979). Possibly, both ideas reinforced one another until the use of kink bands as palaeostress indicator became widely accepted.

Two main mechanisms of kink band formation have been put forward (see overviews in Weiss, 1980; Murphy, 1988; Stubley, 1990 and Sharma and Bhola, 2005). In the first model, termed the kink band boundary migration model or mobile hinge model, kink bands originate as points or line sources, away from which the kink band boundaries migrate (kink band widening) whilst the internal angles between foliation and kink band boundaries remain equal (e.g. Paterson and Weiss, 1962, 1966; Anderson, 1974; Gay and Weiss, 1974; Stewart and Alvarez, 1991). In the second model, termed the rotation model or fixed hinge model, the kink band boundaries are fixed at the onset of kink band development, so that the kinked segment maintains a constant length during rotation (e.g. Donath, 1968; Anderson, 1974; Murphy, 1988; Sharma and Bhola, 2005). Many kink bands exist (as in the present study) in which the angles $\varphi$ and $\varphi_{\mathrm{k}}$ (respectively, $\alpha$ and $\beta$ of Anderson, 1964) are not equal, but in which $\varphi(\alpha)$ is significantly smaller than $\varphi_{\mathrm{k}}(\beta)$ (cf. Figs. 8 and 12), and in which there is no loss of cohesion along the kink band boundaries (Sharma and Bhola, 2005). Such kink 
A

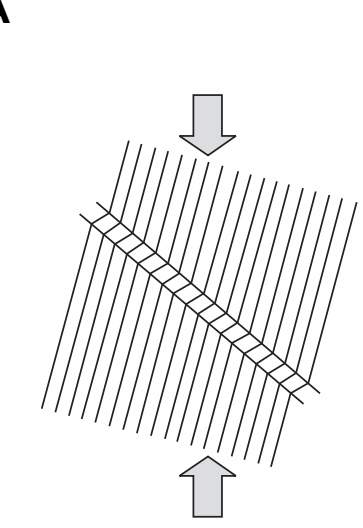

On NE-dipping cleavage: Top-to-Southwest

On clockwise trending cleavage:

Dextral

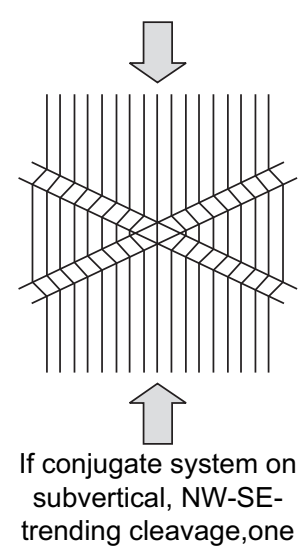

expects:

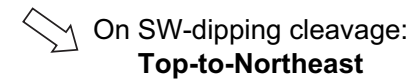

On anticlockwise trending cleavage:

B

\section{Sinistral}

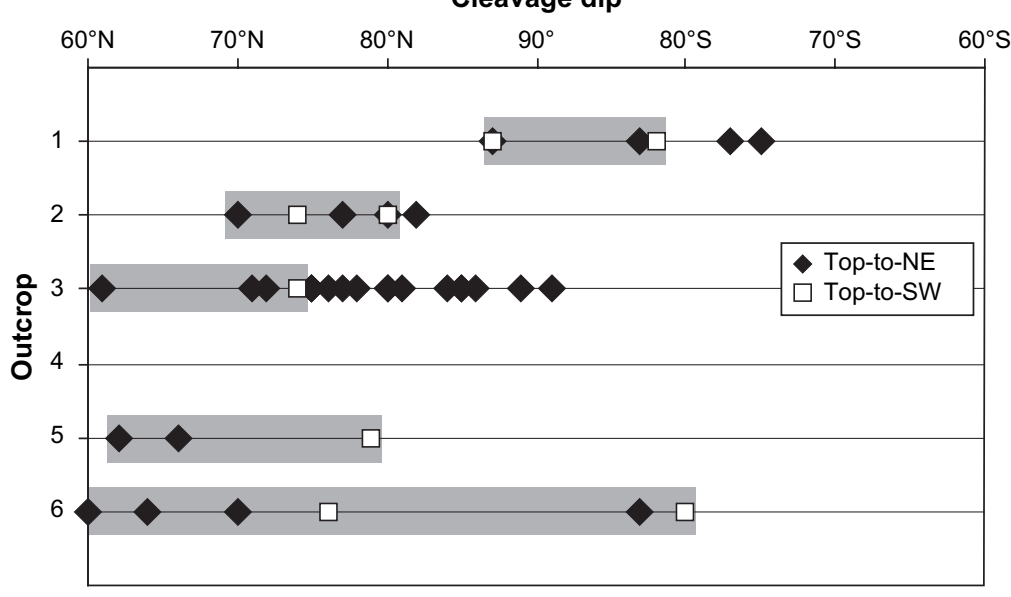

C

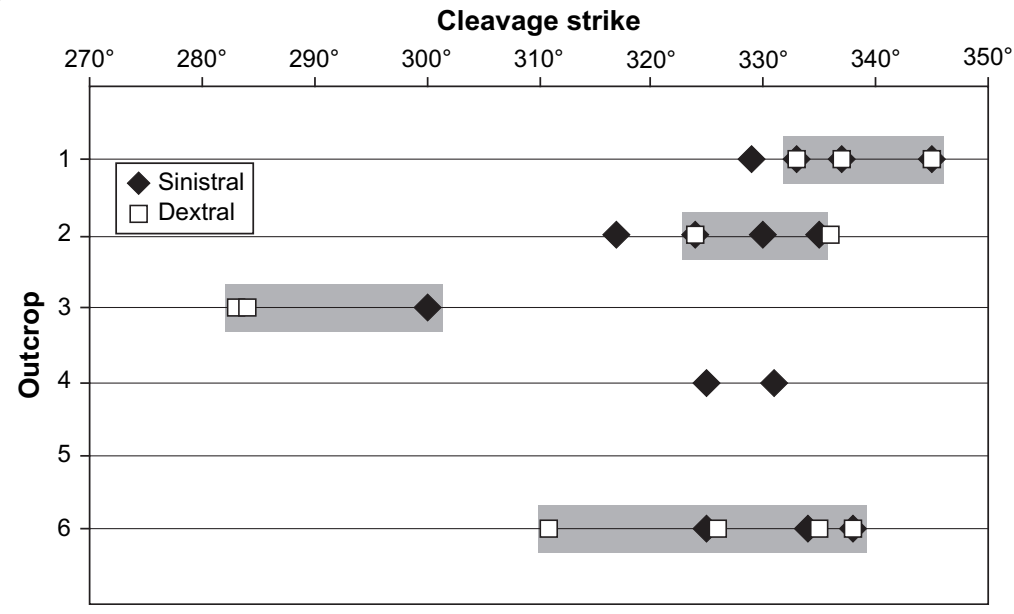

Fig. 13. Schematic representation of observations and problems regarding the kink bands in the Macin zone. (A) Expected kink band geometries for changing cleavage dips and cleavage trends under the influence of a subvertical maximum compression, respectively NW-SE-trending subhorizontal compression. (B) Diagram with the observed occurrence of different types of kink bands with respect to cleavage dip. Judging from the expectations shown in A, the relative occurrence of the different sets allows outlining zones of cleavage dips, marked in grey, in which a conjugate system should occur. (C) Diagram with the observed occurrence of different types of kink bands with respect to cleavage strike. Judging from the expectations shown in A, the relative occurrence of the different sets allows outlining zones of cleavage strikes, marked in grey, in which a conjugate system should occur. Note the large spread in cleavage dip (B) and cleavage strike (C) of the expected and observed conjugate systems, not only in between different outcrops but also within individual outcrops. 


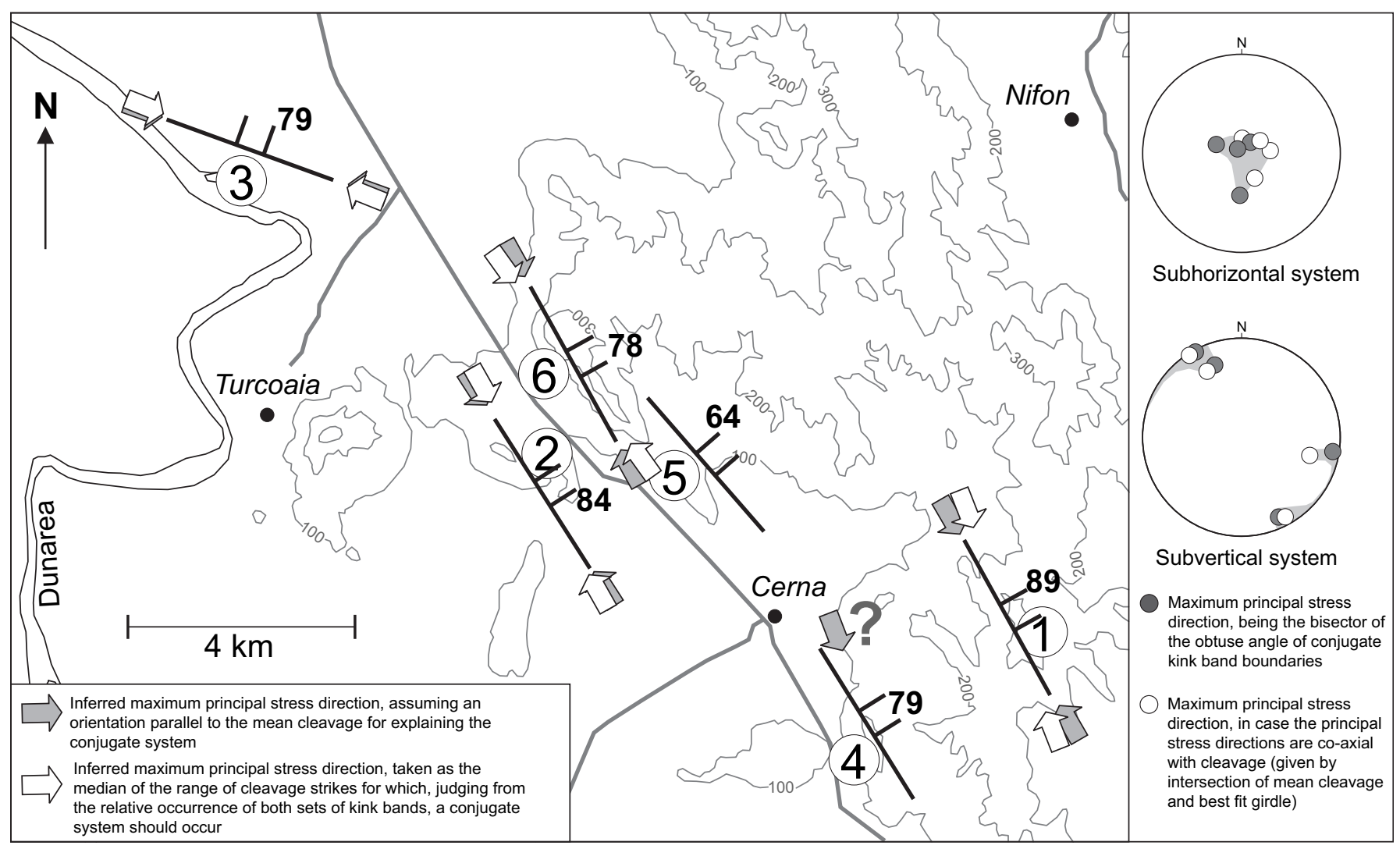

Fig. 14. Inferred maximum compressive palaeostress orientations inferred from the steep kink bands (dextral and sinistral sets) within the Macin zone.

bands are difficult to reconcile with the kink band boundary migration model, unless a significant amount of fabric-parallel slip occurs outside the kink bands (Stubley, 1990; Stewart and Alvarez, 1991; cf. Fig. 15C). In addition, the experiments of Anderson (1974) suggest that, depending on the confining pressure, both models may apply: lateral migration of kink band boundaries at high confining pressures, and the rotation model/fixed hinge model at low confining pressures. If correct, this would point to different modes of kink band development, all giving rise to quite comparable kink band geometries. In turn, if different modes of kink band development exist, the question can be raised whether these kink bands all have an identical relationship with stress orientation.

Studies in which regional palaeostress direction is inferred from kink band geometries rarely consider the kink band formation mechanism or the possibility of stress deflection along the kinked, pre-existing anisotropy (generally cleavage). Moreover, possibly also pre-existing fabrics other than the kinked foliation (e.g. bedding, fractures, faults, etc) may influence the kink band geometry, either by influencing stress orientation or by directly controlling the geometry of the developing kink band. As suggested in the present study, the pre-existing anisotropies may control kink band development in such a way that the relationship between kink bands and regional palaeostress orientation becomes rather complex. Likely, depending on the intensity and relative orientation of the different pre-existing fabrics, different modes of kink band development may operate (cf. Anderson, 1974). This might also explain the wide variety of angles between external foliation and stress for which a single set of kink bands can develop (see Fig. 2). In this respect, it can be questioned in how far all kink bands can truly be used as regionally significant palaeostress indicators. In addition, the anastomosing, periclinal nature of many of the kink bands observed within the North Dobrogea Orogen (e.g. Fig. 10G), and the occurrence of kink bands with curved kink band boundaries and curvilinear kink axes (cf. Kirschner and Teixell, 1996) (Fig. 10H) also put doubt on the direct link of kink band geometry and stress.

\section{Conclusions and recommendations}

Both within the Anglo-Brabant Deformation Belt and the North Dobrogea Orogen, the relative position and orientation of the different kink band sets with respect to cleavage is quite different from what would be expected from previous studies. In both cases, the observations are most easily explained by invoking a stress deflection by/along the pre-existing anisotropy. In the North Dobrogea Orogen, maximum compressive stress appears deflected parallel to the cleavage. In the Anglo-Brabant Deformation Belt, the maximum compressive stress may be deflected subperpendicular to bedding (for unknown reasons), deflected subparallel to cleavage (with the missing set of the conjugate system forming parallel to bedding within specific lithologies and hence resembling a strong cleavage refraction), or the kink bands may result from normal shear along the bedding and cleavage anisotropy under the influence of an overall subvertical stress.

Some observations, such as the anastomosing, periclinal nature of many of the kink bands, and the occurrence of kink bands with curved kink band boundaries (cf. Verbeek, 1978) and curvilinear kink axes, also cast doubt on the relationship between kink band geometry and stress. For a given anisotropic rock, depending on confining pressure, strain, strain rate and temperature, a complete gradation may exist between shear fractures on the one hand and ductile folds on the other hand, with kink bands covering a broad intermediate spectrum (cf. Weiss, 1980). If this is the case, and taking into account the possibility of stress deflection by preexisting anisotropies, not all kink bands will necessarily reflect stress in the way suggested by experiments (e.g. Paterson and Weiss, 1962, 1966; Gay and Weiss, 1974). As a result, caution should 
A

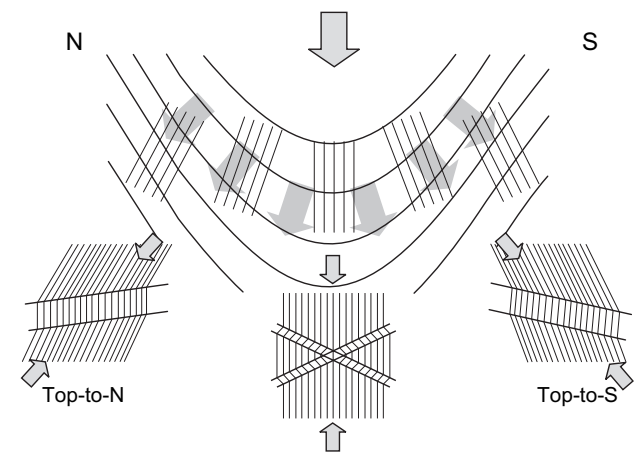

B

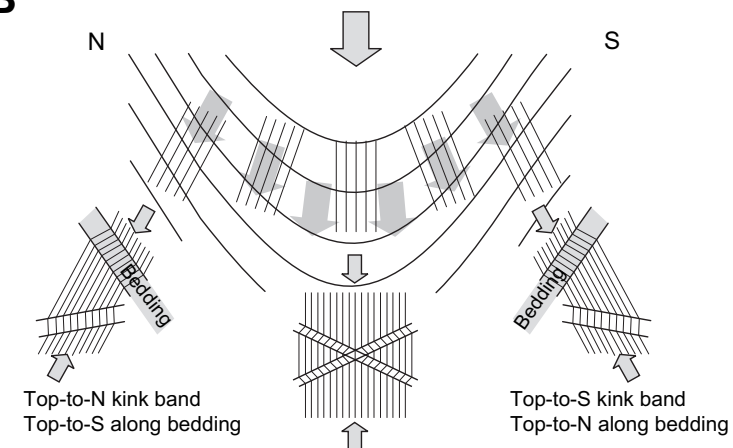

C

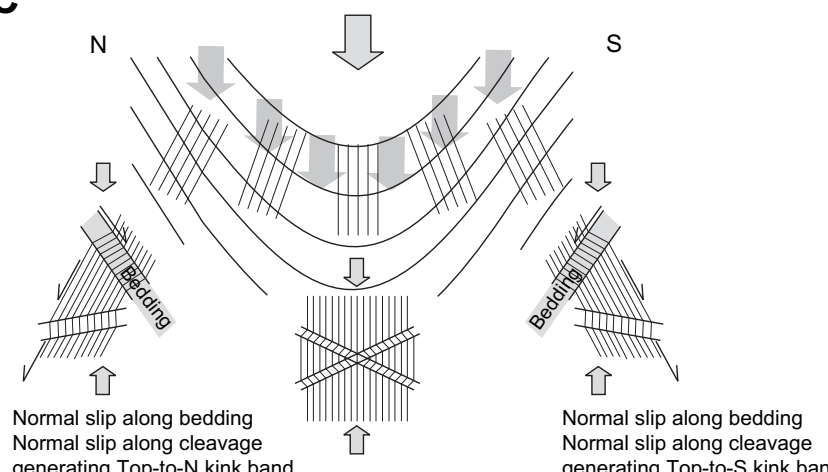

Fig. 15. Schematic representation of the maximum compressive palaeostress orientations inferred from kink bands in the Vichenet section (Anglo-Brabant Deformation Belt). (A) Stress deflection subperpendicular to bedding; (B) stress deflection subparallel to cleavage; and $(C)$ subvertical to steeply S-plunging maximum compressive stress, giving rise to a normal sense of shear along both cleavage and bedding, ultimately resulting in single sets of kink bands, in which the asymmetry is contrary to that expected. See text for explanation.

be used when using kink bands to deduce regional palaeostress patterns.

Ideally, for the purpose of palaeostress analysis, one should use a subhorizontal (subvertical) conjugate system within the hinges of upright, symmetrical, subhorizontal (subvertical) folds, in which the bedding anisotropy can be neglected with respect to cleavage anisotropy. Also in cases in which conjugate systems are rare, but in which both sets are observed individually, attention should be concentrated primarily on the fold hinges. If the orientation of the conjugate system or the orientation of the individual kink band sets changes across a fold, whether or not related to changes in cleavage orientation, a control by the pre-existing fabric(s) should be considered, especially within the fold limbs. A single set of kink band should not be used for palaeostress inferences, even in an approximate way, unless the absence of any control of pre-existing anisotropies other than the kinked anisotropy can be demonstrated. Even in the most ideal cases, regional variations in the main, kinked anisotropy may exist that, because of stress deflection along the anisotropy, are not reflected by the kink band orientation and geometry. In such cases, one should determine palaeostress using the mean, median and extreme orientation values, one should present the palaeostress results only as such (with corresponding error margin), and one should not extrapolate the inferred palaeostress outside the region under study.

\section{Acknowledgements}

The authors wish to acknowledge B. Goscombe, D. Srivastava and T. Blenkinsop for their constructive remarks on the manuscript, and are grateful to G. Oaie and M. Vaida for the support during the fieldwork in North Dobrogea (Romania). T.N. Debacker is a Postdoctoral Fellow of the Fund for Scientific Research-Flanders (F.W.O.-Vlaanderen) and M. Sintubin a Research Associate of the "Onderzoeksfonds, K.U.Leuven". This work, resulting from fieldwork when T. Debacker was at the Katholieke Universiteit Leuven (2002-2005), forms part of research projects G.0274.99, G.0094.01 and G.0271.05 of the F.W.O.-Vlaanderen. The research in Romania benefited from the International scientific and technological cooperation program from the Science, Innovation and Media Department of the Ministry of the Flemish Community (BIL01/34).

\section{References}

Anderson, E.M., 1951. The Dynamics of Faulting and Dyke Formation with Applications to Britain, revised second ed. Oliver and Boyd, Edinburgh.

Anderson, T.B., 1964. Kink-bands and related geological structures. Nature 202 272-274.

Anderson, T.B., 1974. The relationship between kink-bands and shear fractures in the experimental deformation of slate. Journal of the Geological Society, London 130, 367-382.

Angelier, J., 1979. Determination of the mean principal directions of stresses for a given fault population. Tectonophysics 56, T17-T26.

Belmans, M., 2000. Structurele geologie van het Siluur uit de Orneauvallei, Massief van Brabant. M.Sc. thesis, Universiteit Gent.

Bouma, A.H., 1962. Sedimentology of Some Flysch Deposits. Elsevier, Amsterdam.

Cobbold, P.R., Cosgrove, J.W., Summers, J.M., 1971. Development of internal structures in deformed anisotropic rocks. Tectonophysics 12, 23-53.

Debacker, T.N., 2001. Palaeozoic Deformation of the Brabant Massif within Eastern Avalonia: How, When and Why? Ph.D. thesis, Universiteit Gent

Debacker, T.N., 2002. Cleavage/fold relationship in the Silurian of the Mehaigne-Burdinale area, southeastern Brabant Massif, Belgium. Geologica Belgica 5 , 3-15.

Debacker, T.N., Dewaele, S., Sintubin, M., Verniers, J., Muchez, Ph., Boven, A., 2005a. Timing and duration of the progressive deformation of the Brabant Massif, Belgium. Geologica Belgica 8, 20-34.

Debacker, T.N., Robion, P., Sintubin, M., 2005b. Complexity of the anisotropy of magnetic susceptibility in single-phase deformed, low-grade, cleaved mudstone. Materials Science Forum 495-497, 45-50.

Debacker, T.N., Robion, P., Sintubin, M., 2004a. The anisotropy of magnetic susceptibility (AMS) in low-grade, cleaved pelitic rocks: influence of cleavage/ bedding angle and type and relative orientation of magnetic carriers. In: Martin-Hernandez, F., Lüneburg, C.M., Aubourg, C., Jackson, M. (Eds.), Magnetic Fabric: Methods and Applications. Geological Society of London, Specia Publications, vol. 238, pp. 77-107.

Debacker, T.N., Herbosch, A., Verniers, J., Sintubin, M., 2004b. Faults in the Asquempont area, southern Brabant Massif, Belgium. Netherlands Journal of Geosciences 83, 49-65.

Debacker, T.N., Sintubin, M., Verniers, J., 1999. Cleavage/fold relationships in the Silurian metapelites, southeastern Anglo-Brabant fold belt (Ronquières, Belgium). Geologie \& Mijnbouw 78, 47-56.

De Vos, W., Verniers, J., Herbosch, A., Vanguestaine, M., 1993. A new geological map of the Brabant Massif, Belgium. Geological Magazine 130, 605-611.

Dewey, J.F., 1965. Nature and origin of kink-bands. Tectonophysics 1, 459-494.

Dewey, J.F., 1966. Kink-bands in Lower Carboniferous slates of Rush, Co. Dublin. Geological Magazine 103, 138-142.

Donath, F.A., 1968. Experimental study of kink-band development in the Martinsburg Slate. Geological Survey of Canada Paper 68-52, 255-288.

Donath, F.A., 1972. Effects of cohesion and granularity on deformation behaviour of anisotropic rock. Geological Society of America Memoir 135, 95-128.

Gay, N.C., Weiss, L.E., 1974. The relationship between principal stress directions and the geometry of kinks in foliated rocks. Tectonophysics 21, 287-300.

Goscombe, B.D., Findlay, R.H., Mcclenaghan, M.P., Everard, J., 1994. Multiscale kinking in northeast Tasmania - crustal shortening at shallow crustal levels. Journal of Structural Geology 16, 1077-1092. 
Herbosch, A., Verniers, J., Debacker, T.N., Billiaert, B., De Schepper, S., Belmans, M., 2002. The Lower Palaeozoic stratigraphy and sedimentology of the Brabant Massif in the Dyle and Orneau valleys and of the Condroz Inlier at Fosses: an excursion guidebook. Geologica Belgica 5, 71-143.

Hippolyte, J.-C., 2002. Geodynamics of Dobrogea (Romania): new constraints on the evolution of the Tornquist-Teisseyre Line, the Black Sea and the Carpathians. Tectonophysics 357, 33-53.

Hobson, D.M., 1973. The origin of kink bands near Tintagel, North Cornwall. Geological Magazine 110, 133-144

Johnson, M.R.W., 1956. Conjugate fold systems in the Moine Thrust Zone in the Lochcarron and Coulin Forest areas of Wester Ross. Geological Magazine 93, 345-350.

Kaisin, F., 1933. Contribution à l'étude tectonique du Bassin de Namur, Troisième note: Etude de la bordure septentrionale du bassin et conclusions generales. Annales de la Société belge de Géologie 43, 334-377.

Kirschner, D.L., Teixell, A., 1996. Three-dimensional geometry of kink bands in slates and its relationship with finite strain. Tectonophysics 262, 195-211.

Kleist, J.R., 1972. Kink bands along the Denali Fault, Alaska. Bulletin of the Geological Society of America 83, 3487-3490.

Konopasek, J., Schulmann, K., Lexa, O., 2001. Structural evolution of the central part of the Krusné hory (Erzgebirge) Mountains in the Czech Republic - evidence for changing stress regime during Variscan compression. Journal of Structural Geology 23, 1373-1392.

Legrand, R., 1967. Ronquières, documents géologiques. Mémoire pour servir à l'Explication des Cartes géologiques et minières de la Belgique 6, 1-60.

Legrand, R., 1968. Le Massif du Brabant. Mémoire pour servir à l'Explication des Cartes géologiques et minières de la Belgique 9, 1-148

Mortelmans, G., 1953. Efforts calédoniens et efforts hercyniens dans le silurien de la vallée de l'Orneau. Bulletin de la Société belge de Géologie, de Paléontologie et d'Hydrologie 62, 143-164.

Murphy, F.X., 1988. The origin of Variscan kink bands: a study from the Dungarvan Syncline, southern Ireland. Geological Magazine 125, 641-650.

Paterson, M.S., Weiss, L.E., 1962. Experimental folding in rocks. Nature 195, 1046-1048.

Paterson, M.S., Weiss, L.E., 1966. Experimental deformation and folding in phyllite. Bulletin of the Geological Society of America 77, 343-374.

Pratt, W.T., 1992. The use of kink bands to constrain fault displacements: an example from the Bala Lineament, Wales. Geological Magazine 129, 625-632.

Ramsay, J.G., 1962. The geometry of conjugate fold systems. Geological Magazine 99, 516-526.

Ramsay, J.G., Huber, M.I., 1987. The techniques of modern structural geology. In: Folds and Fractures, vol. 2. Academic Press, London.

Seghedi, A., 2001. The North Dobrogea orogenic belt (Romania): a review. In: Ziegler, P.A., Cavazza, W., Robertson, A.H.F., Crasquin-Soleau, S. (Eds.), Peri-
Tethys Memoir 6: peri-Tethyan Rift/Wrench Basins and Passive Margins. Mémoires du Muséum National d'Histoire Naturelle 186, 237-257.

Sharma, B.K., Bhola, A.M., 2005. Kink bands in the Chamba region, Western Himalaya, India. Journal of Asian Earth Sciences 25, 513-528.

Sintubin, M., 1997. Cleavage-fold relationships in the Lower Paleozoic Brabant Massif (Belgium). Aardkundige Mededelingen 8, 161-164.

Sintubin, M., 1999. Arcuate fold and cleavage patterns in the southeastern part of the Anglo-Brabant Fold Belt (Belgium): tectonic implications. Tectonophysics 309, 81-97.

Srivastava, D.C., Lisle, J.R., Imran, M., Kandpal, R., 1998. The kink-band triangle: a triangular plot for paleostress analysis from kink-bands. Journal of Structural Geology 20, 1579-1586.

Srivastava, D.C., Lisle, J.R., Imran, M., Kandpal, R., 1999. A new approach for palaeostress analysis from kink bands: application of fault-slip methods. Journal of Geology 107, 165-176.

Stewart, K.G., Alvarez, W., 1991. Mobile-hinge kinking in layered rocks and models. Journal of Structural Geology 13, 243-259.

Stubley, M.P., 1990. The geometry and kinematics of a suite of conjugate kink bands, southeastern Australia. Journal of Structural Geology 12, 1019-1031.

Vandenven, G., 1967. Les remaniements de la schistosité des roches siluriennes dans la bordure méridionale du Massif du Brabant. Annales de la Société Géologique de Belgique 90, 519-531.

Van Grootel, G., Verniers, J., Geerkens, B., Laduron, D., Verhaeren, M., Hertogen, J., De Vos, W., 1997. Timing of subsidence-related magmatism, foreland basin development, metamorphism and inversion in the Anglo-Brabant fold belt. Geological Magazine 134, 607-616.

Verbeek, E.R., 1978. Kink bands in the Somport slates, west-central Pyrenees, France and Spain. Bulletin of the Geological Society of America 89, 814-824.

Verniers, J., Herbosch, A., Vanguestaine, M., Geukens, F., Delcambre, B., Pingot, J.L., Belanger, I., Hennebert, M., Debacker, T., Sintubin, M., De Vos, W., 2001. Cambrian-Ordovician-Silurian lithostratigraphical units (Belgium). Geologica Belgica 4, 5-38.

Verniers, J., Pharaoh, T., André, L., Debacker, T., De Vos, W., Everaerts, M., Herbosch, A., Samuelsson, J., Sintubin, M., Vecoli, M., 2002. The Cambrian to mid Devonian basin development and deformation history of Eastern Avalonia, east of the Midlands Microcraton: new data and a review. In: Winchester, J.A., Pharaoh, T.C., Verniers, J. (Eds.), Palaeozoic Amalgamation of Central Europe. Geological Society of London, Special Publications, vol. 201, pp. 47-93.

Verniers, J., Van Grootel, G., 1991. Review of the Silurian in the Brabant Massif, Belgium. Annales de la Société Géologique de Belgique 114, 163-193.

Weiss, L.E., 1980. Nucleation and growth of kink bands. Tectonophysics 65, $1-38$.

Zandvliet, J., 1960. The geology of the upper Salat and Pallaresa Valleys, Central Pyrenees, France/Spain. Leidse Geologische Mededelingen 25, 1-127. 